Transactions of the Royal Society of Tropical Medicine and Hygiene (1990) 84, 84-88

\title{
Ultrasound scanning for detecting morbidity due to Schistosoma haematobium and its resolution following treatment with different doses of praziquantel
}

C. Hatz ${ }^{1}$, C. Mayombana ${ }^{1}$, D. de Savigny ${ }^{1}$, C. N. L. MacPherson ${ }^{1}$, J. C. Koella ${ }^{2}$, A. Degrémont ${ }^{2}$ and M. Tanner ${ }^{2}$ Swiss Tropical Institute Field Laboratory, P.O. Box 53, Ifakara, Tanzania; ${ }^{2}$ Swiss Tropical Institute, P.O. Box, CH-4002 Basel, Switzerland

\section{Abstract}

A study to assess the resolution of urinary tract morbidity due to Schistosoma haematobium was conducted on 2 cohorts of schoolchildren attending neighbouring schools in Kilombero District, southern Tanzania. Schoolchildren were screened for $S$. haematobium infection using the standard World Health Organization filtration technique and subsequently examined for urinary tract pathology using a portable $3.0 \mathrm{MHz}$ sector scanner (Siemens Sonoline 1300). Treatment with praziquantel was given to all infected children. Children with observed urinary tract pathology received either $20(n=52)$ or $40(n=79) \mathrm{mg} / \mathrm{kg}$ body weight and were sonographically re-examined one, 2, 3 and 6 months following treatment. Geometric mean outputs of 21 and $19 \mathrm{eggs} / \mathrm{ml}$ of urine were detected in the 2 cohorts before treatment. Urinary tract pathology correlated positively with egg output $\left(\chi^{2}, P=0.02\right)$ and microhaematuria $(P=0.0001)$. Bladder (wall irregularities and polyps) and kidney (congestive changes) pathologies were found in $81 \%$ and $36 \%$, respectively, of the group that received $20 \mathrm{mg} / \mathrm{kg}$ of praziquantel, and in $78 \%$ and $46 \%$ of the group that received $40 \mathrm{mg} / \mathrm{kg}$. Six months after treatment, $90.4 \%$ and $88.0 \%$ parasitological cure rates were obtained using 20 or $40 \mathrm{mg}$ praziquantel $/ \mathrm{kg}$ body weight. The respective pathology clearances were $88 \%$ and $91 \% .20 \mathrm{mg} / \mathrm{kg}$ of praziquantel was as effective with regard to cure rates and reversibility of morbidity as $40 \mathrm{mg} / \mathrm{kg}$.

\section{Introduction}

Reduction of morbidity is the immediate aim of the global strategy to control schistosomiasis (WHO, 1985). Published reports of methods to diagnose Schistosoma haematobium infection and to measure the effect of control measures (BRINKMANN $e t$ al., 1988) rely on laboratory investigations rather than on direct assessment of pathology. Infection with $S$. haematobium causes upper and lower urinary tract lesions. Intravenous pyelography (FORSYTH, 1965), cystoscopy and computerized tomography (AISEN, 1983) have been used in the past to detect such lesions, but the invasive nature of such investigations, which must be confined to hospital settings, made it difficult to carry out longitudinal studies (MACDONALD et al., 1968).

Using ultrasound to assess urinary tract lesions permits the investigation of affected populations at community level (DEGRÉmONT et al., 1985). The

Correspondence and reprint requests: $\operatorname{Dr} M$. Tanner, Department of Public Health and Epidemiology, Swiss Tropical Institute, P.O. Box, 4002 Basel, Switzerland. efficiency of ultrasound in detecting lesions has been demonstrated in comparison with intravenous pyelography and cystoscopy (BURKI et al., 1986). Reports on the evolution of obstructive uropathy after treatment have recently been published (DOEHRING et al., 1985; KING et al., 1988), but no detailed follow-up of pathology clearance has yet been presented.

Recent work suggests that morbidity control may be achieved by lower dosages of praziquantel than those currently recommended (WILKINS \& MOORE, 1987; TAYLOR et al., 1988). Because of a proposal to treat all positive schoolchildren in the Kilombero District, south-east Tanzania, we tested the economical regimen of administering $20 \mathrm{mg} / \mathrm{kg}$ body weight doses of praziquantel.

Morbidity control strategies require a careful monitoring of direct and indirect morbidity indicators in order to determine treatment and retreatment cycles in different endemic settings. Considering this priority in schistosomiasis control, this study was aimed at following the evolution over 6 months of uropathy related to $S$. haematobium following 2 different regimens of praziquantel using ultrasound as a tool for direct detection of morbidity.

\section{Materials and Methods}

Study area

The study was carried out in a rural area of south-east Tanzania from March to September 1986 and from February to August 1988 with pupils from 2 neighbouring schools, Kibaoni and Milola. S. haematobium is endemic in the area and has been investigated previously (ZUMSTEIN, 1983).

\section{Study population}

202 pupils aged 7 to 20 years (mean 12.6) entered the study from Milola school and 236 pupils aged 8 to 17 years (mean 12.4) from Kibaoni school. The study was approved by the Tanzania Medical Research Council (UTAFITI) and informed consent was obtained locally at the schools from pupils, their parents and teachers. The latter participated actively in the health education during the surveys.

\section{Laboratory methods}

Filtrations of $10 \mathrm{ml}$ of urine per child were done on 5 consecutive days between 1000 and $1330 \mathrm{~h}$, using Nuclepore membranes (12 $\mu \mathrm{m})$ (ZUMSTEIN, 1983). The urine was examined for microhaematuria, proteinuria and leucocyturia with Combur-9 reagent strips (Boehringer). Level of infection was estimated 
for each individual by the maximum egg output of his or her 5 daily urine samples.

257 children (117 at Milola and 140 at Kibaoni schools) with positive egg counts were re-examined regularly until 6 months after treatment.

\section{Sonography}

A brief clinical examination was carried out in all children and the urine was checked for macrohaematuria. All children underwent a comprehensive ultrasound examination of the urinary tract. A Siemens 3.0 $\mathrm{MHz}$ sector scanner (Sonoline 1300) was used, powered by a portable generator. Pupils were examined in the supine position. Congestive changes of the kidneys were recorded according to ELLENBOGEN (1978) with slight modifications: fissures of both left and right kidneys were considered normal to minimize any possible interpretation bias at low pathology level. Pathology was recorded as mild congestion, moderate congestion, or severe congestion with hydronephrosis. Ureters were checked for congestion. All children with congestive changes were asked to empty their bladders and were re-examined to prevent a wrong interpretation of congestion due to a full bladder (MORIN \& BAKER, 1979). Other kidney pathology (blurred central echo complex) was not included in the evaluation. The interpretation of the bladder wall structure was made according to its surface regularity, thickness and tumors. Thickness was measured at the back wall and recorded as pathological when $>5 \mathrm{~mm}$ (BURKI et al., 1986). Any calcifications were recorded.

\section{Treatment and follow-up}

Pupils at the two schools were treated with praziquantel at a single dose of $40 \mathrm{mg} / \mathrm{kg}$ and $20 \mathrm{mg} / \mathrm{kg}$ respectively. Due to operational reasons there was no within-school randomization for the 2 doses of praziquantel. The treatment was administered during the season of low transmission when small numbers of infected snails are found (SUTER, 1986).

124 infected pupils with pathology were re-examined after treatment. The 72 pupils from Milola school (40 mg group) underwent further scanning after one, 2 and 6 months, and the 52 pupils from Kibaoni school (20 mg group) were rescanned after 3 and 6 months. We did not include a non-treated control group for ethical reasons.

\section{Statistical analysis}

Geometric mean of $(x+1)$ eggs per $10 \mathrm{ml}$ of urine was used. Wherever appropriate, the $\chi^{2}$ test, $t$-test, analysis of covariance (ANCOVA) or regression were applied for statistical analysis.

\section{Results}

The overall prevalence of $S$. haematobium infections at Milola $(n=202)$ and Kibaoni $(n=236)$ schools was $64.9 \%(95 \%$ confidence interval $[\mathrm{CI}] 58 \cdot 3-71 \cdot 5)$ and $59 \cdot 3 \%(95 \%$ CI $53 \cdot 3-65 \cdot 5)$. The overall pathology rate was $47 \cdot 5 \%(95 \% \mathrm{CI} 40 \cdot 6-54 \cdot 4)$ and $41 \cdot 1 \%(95 \% \mathrm{CI}$ $34 \cdot 8-47 \cdot 4)$. Analysis of covariance showed that pathology was positively associated with age $(F=5 \cdot 4$, $P=0.02)$ but not with sex $(F=0.5, P=0.5)$. The laboratory follow-up investigations revealed no difference in infection, intensity or clearance rates between boys and girls.

117 children from Milola school and 140 from Kibaoni school were admitted to the study in order to evaluate the efficacy of a reduced dosage $(20 \mathrm{mg} / \mathrm{kg}$ ) of praziquantel. The pre- and post-treatment geometric mean egg outputs for the treatment groups are listed in Table 1. No significant difference was observed between the 2 treatment groups. Parasitological clearance rates are shown in Table 2 .

Seventy-two and 52 pupils with uropathy were followed sonographically at Milola (40 mg group) and Kibaoni (20 mg group) schools for a period of 6 months after treatment. Bladder pathology was found initially in $81 \%$ of the group who received $20 \mathrm{mg} / \mathrm{kg}$ of praziquantel and in $78 \%$ of the $40 \mathrm{mg} / \mathrm{kg}$ group. Congestive changes were found in $36 \%$ and $46 \%$ of the kidneys. Moderate to severe congestion and hydronephrosis were recorded in $3 \%$ and $16 \%$ of all kidneys. Bladder pathology was not present in 3 pupils $(84 \%)$ with moderate congestion. In one of these cases, the congestion resolved within 2 months after chemotherapy. Pathology of the left and right kidneys was recorded in $38 \%$ and $33 \%$ respectively in the $20 \mathrm{mg} / \mathrm{kg}$ group, and in $52 \%$ and $42 \%$ in the $40 \mathrm{mg} / \mathrm{kg}$ group.

Bladder and kidney pathology correlated positively with egg output $(P<0.02)$ and microhaematuria $(P<0.001)$ in both groups. Pathological changes did not differ $(P=0 \cdot 2)$ in children with heavy $(>100$ eggs per $10 \mathrm{ml}$ of urine) and light infections (<100 eggs).

The evolution of urinary tract lesions is shown in Figs 1 and 2. The regression curves indicate that bladder pathology clearance was similar in both treatment groups, but that the clearance of kidney pathology tended to be slower in the first 3 months in

Table 1. Geometric mean egg outputs before and after treatment with two dosages of praziquantel

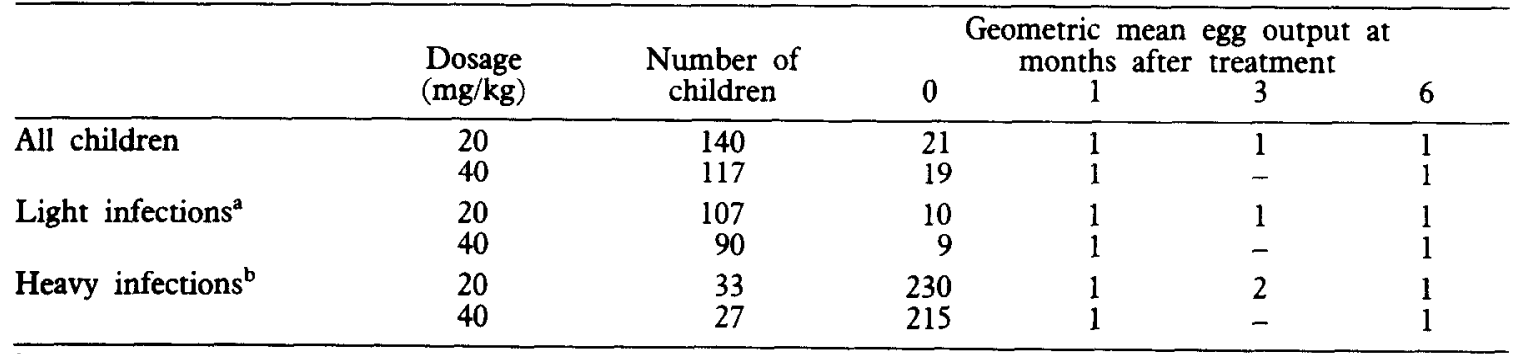

$<100 \mathrm{eggs} / 10 \mathrm{ml}$ urine.

${ }^{b} \geqslant 100 \mathrm{eggs} / 10 \mathrm{ml}$ urine. 
Table 2. Parasitological clearance rates after treatment with two dosages of praziquantel

\begin{tabular}{|c|c|c|c|c|c|}
\hline & $\begin{array}{l}\text { Dosage } \\
(\mathbf{m g} / \mathbf{k g})\end{array}$ & $\begin{array}{l}\text { Number of } \\
\text { children }\end{array}$ & \multicolumn{3}{|c|}{$\begin{array}{l}\text { Clearance rates }{ }^{\mathrm{b}} \text { at } \\
\text { months after treatment }\end{array}$} \\
\hline $\begin{array}{l}\text { All children } \\
\text { Standard error } \\
\text { Significance }\end{array}$ & $\begin{array}{l}20 \\
40\end{array}$ & $\begin{array}{l}140 \\
117\end{array}$ & $\begin{array}{c}98.0 \\
80.0 \\
3.9 \\
P<0.005\end{array}$ & $\begin{array}{l}90 \cdot 0 \\
-\end{array}$ & $\begin{array}{r}90 \cdot 0 \\
88 \cdot 0 \\
3.9 \\
\text { NS }\end{array}$ \\
\hline $\begin{array}{l}\text { Light infections }{ }^{c} \\
\text { Standard error } \\
\text { Significance }\end{array}$ & $\begin{array}{l}20 \\
40\end{array}$ & $\begin{array}{r}107 \\
90\end{array}$ & $\begin{array}{c}99.0 \\
86.0 \\
3.8 \\
P<0.001\end{array}$ & $\begin{array}{c}91 \cdot 0 \\
-\end{array}$ & $\begin{array}{r}94 \cdot 0 \\
91 \cdot 0 \\
3 \cdot 8 \\
\text { NS }\end{array}$ \\
\hline $\begin{array}{l}\text { Heavy infections } \\
\\
\text { Standard error } \\
\text { Significance }\end{array}$ & $\begin{array}{l}20 \\
40\end{array}$ & $\begin{array}{l}33 \\
27\end{array}$ & $\begin{array}{c}94 \cdot 0 \\
63 \cdot 0 \\
10 \cdot 2 \\
P<0 \cdot 01\end{array}$ & $\begin{array}{c}87 \cdot 0 \\
-\end{array}$ & $\begin{array}{l}79 \cdot 0 \\
78 \cdot 0 \\
10 \cdot 7 \\
\text { NS }\end{array}$ \\
\hline
\end{tabular}

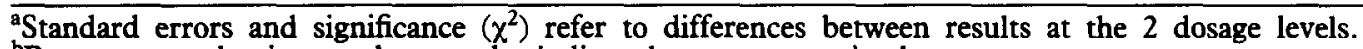

bercentage reduction at the months indicated; $-=$ not examined.

${ }^{c}<100$ eggs $/ 10 \mathrm{ml}$ urine.

$\stackrel{d}{2} 100 \mathrm{eggs} / 10 \mathrm{ml}$ urine.

Table 3. Clearance rates of bladder pathology following treatment with different praziquantel dosages

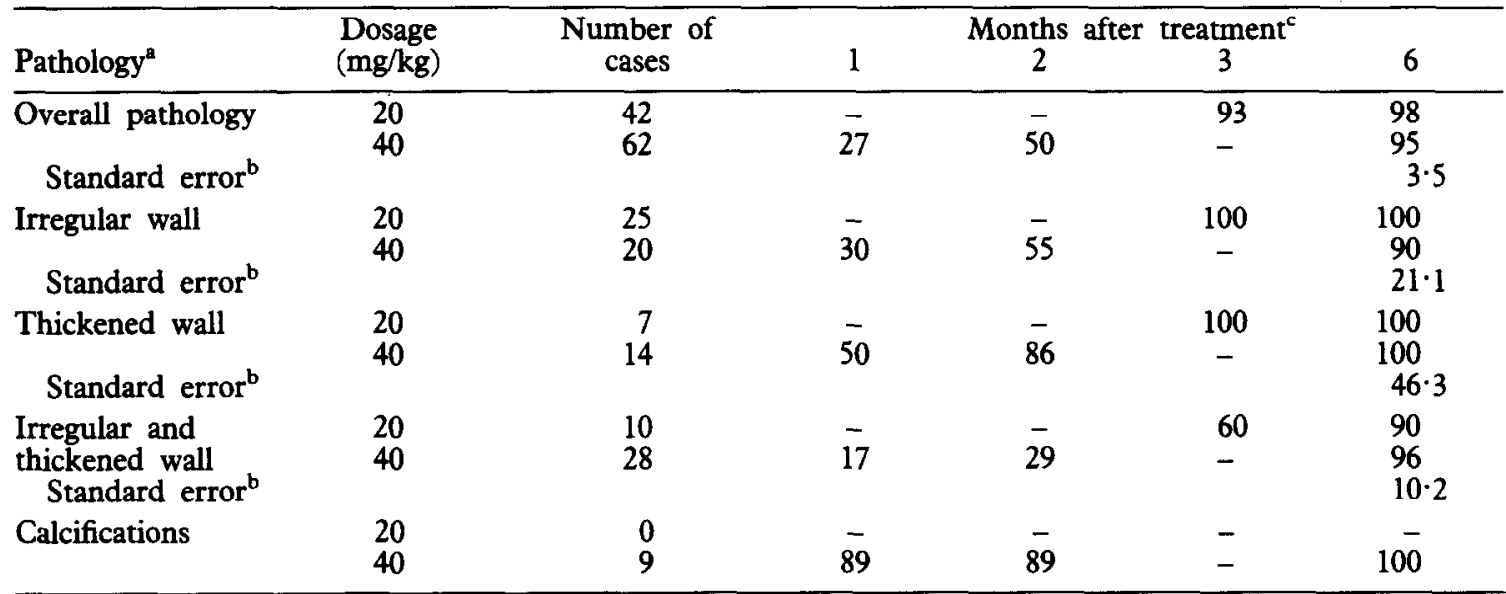

aThe classification of pathology follows ELLENBOGEN et al. (1978) and BURKI et al. (1986) as described in Material and Methods section.

'Standard errors refer to differences between results at the 2 dosage levels; no difference was significant $\left(\chi^{2}\right.$; $P>0.05$ ).

'Percentage reduction at the months indicated; $-=$ not examined.

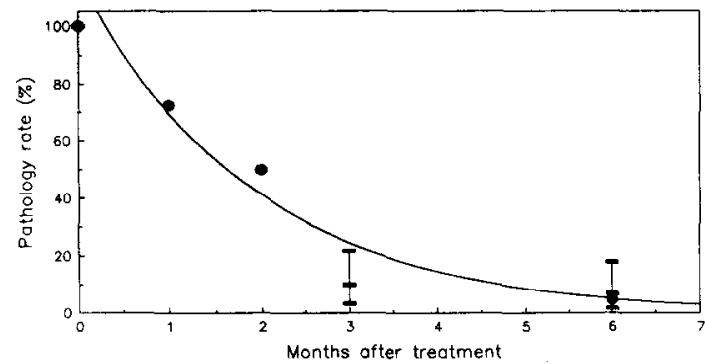

Fig. 1. Bladder pathology rate following treatment with $40 \mathrm{mg} / \mathrm{kg}$ (O) or $20 \mathrm{mg} / \mathrm{kg}(-)$ of praziquantel. The line shows the exponential clearance (percentage reduction) fitted by regression analysis to the $40 \mathrm{mg}$ group. The vertical bars delimit the $95 \%$ confidence intervals of the $20 \mathrm{mg}$ group and indicate the difference from the clearance in the $40 \mathrm{mg}$ group.

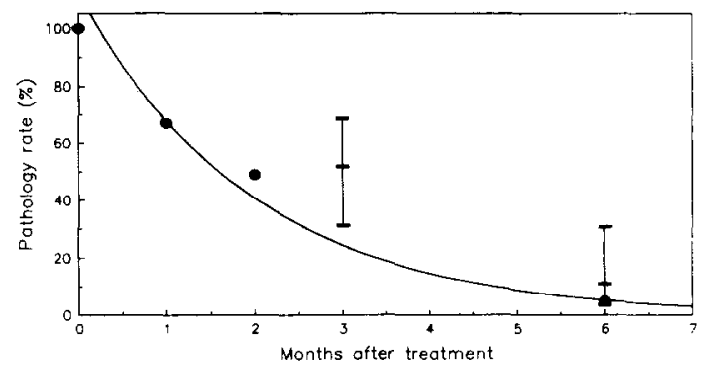

Fig. 2. Kidney pathology rate following treatment with $40 \mathrm{mg} / \mathrm{kg}$ (O) or $20 \mathrm{mg} / \mathrm{kg} \mathrm{(-)}$ of praziquantel. The line shows the exponential clearance (percentage reduction) fitted by regression analysis to the $40 \mathrm{mg}$ group. The vertical bars delimit the $95 \%$ confidence intervals of the $20 \mathrm{mg}$ group and indicate the difference from the clearance in the $40 \mathrm{mg}$ group. 
Table 4. Clearance rates of kidney pathology following treatment with different praziquantel dosages

\begin{tabular}{|c|c|c|c|c|c|c|}
\hline Pathology ${ }^{d}$ & $\begin{array}{c}\text { Dosage } \\
(\mathrm{mg} / \mathrm{kg})^{\mathrm{b}}\end{array}$ & $\begin{array}{l}\text { Number of } \\
\text { congested } \\
\text { kidneys }\end{array}$ & \multicolumn{4}{|c|}{ Months after treatment ${ }^{c}$} \\
\hline $\begin{array}{l}\text { Overall pathology } \\
\text { Standard error }\end{array}$ & $\begin{array}{l}20 \\
40\end{array}$ & $\begin{array}{l}37 \\
73\end{array}$ & $\overline{33}$ & $\overline{51}$ & $\begin{array}{c}48 \\
-\end{array}$ & $\begin{array}{l}89 \\
95 \\
5 \cdot 7\end{array}$ \\
\hline $\begin{array}{l}\text { Mild congestion } \\
\text { Standard error }\end{array}$ & $\begin{array}{l}20 \\
40\end{array}$ & $\begin{array}{l}34 \\
47\end{array}$ & $\overline{45}$ & $\overline{62}$ & $\begin{array}{c}74 \\
-\end{array}$ & $\begin{array}{l}88 \\
96 \\
6 \cdot 3\end{array}$ \\
\hline $\begin{array}{l}\text { Moderate congestion } \\
\text { Standard error }\end{array}$ & $\begin{array}{l}20 \\
40\end{array}$ & $\begin{array}{r}3 \\
24\end{array}$ & $\overline{13}$ & $\overline{38}$ & $\begin{array}{c}67 \\
-\end{array}$ & $\begin{array}{l}100 \\
96 \\
57 \cdot 9\end{array}$ \\
\hline Severe congestion & $\begin{array}{l}20 \\
40\end{array}$ & $\begin{array}{l}0 \\
2\end{array}$ & - & - & - & $5 \overline{0}$ \\
\hline
\end{tabular}

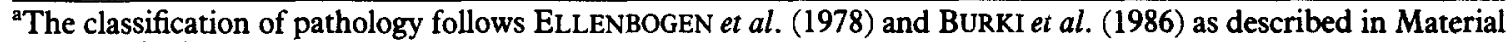
and Methods section.

${ }^{b}$ Standard errors refer to differences between results at the 2 dosage levels; no difference was significant $\left(\chi^{2}\right.$; $P>0.05$ ).

'Percentage reduction at the months indicated; $-=$ not examined.

the $20 \mathrm{mg} / \mathrm{kg}$ group than in the $40 \mathrm{mg} / \mathrm{kg}$ group. There was no significant difference in clearance rates of the $20 \mathrm{mg}$ and the $40 \mathrm{mg}$ groups after 6 months. The detailed evolution of uropathy in the two groups is shown in Tables 3 and 4.

Calcifications were demonstrated in 9 pupils (11\%) at Milola school ( $40 \mathrm{mg} / \mathrm{kg}$ group). Clearance was complete in all 9 cases within 6 months. No calcifications were recorded among the children of Kibaoni school.

\section{Discussion}

This study indicates that in children recently infected with $S$. haematobium the related uropathy can improve greatly within 6 months after chemotherapy in an area of mild to moderate endemicity. Both bladder and kidney pathologies developed favourably after the 2 dosages of praziquantel. Kidney congestion appeared to improve readily after resolution of the obstruction at bladder or ureter level. This may be due to the fact that we saw mainly mild congestive uropathy of possibly recent nature. Reversal is more likely with mild congestion than for chronic, more severe congestive pathology. Our findings contrast with the results of KING et al. (1988), who recorded delayed clearance of kidney pathology in coastal Kenya. This difference may have been due to longer-standing disease or to other factors related to transmission and host defence, bacterial superinfection, or even to reinfections. Our own data (not shown) indicate that pathology due to reinfection can develop within 6-12 months after treatment with $40 \mathrm{mg} / \mathrm{kg}$ of praziquantel.

Kidney pathology clearance tended to be slower in the first 3 months in the group that received $20 \mathrm{mg} / \mathrm{kg}$ of praziquantel. However, the resolution of kidney congestion after six months, and the parasitological clearance rates, suggest comparable efficacies of $20 \mathrm{mg} / \mathrm{kg}$ and $40 \mathrm{mg} / \mathrm{kg}$ of praziquantel.

The 3 pupils with moderate congestive changes of the kidneys but no bladder pathology may have recently received antischistosomal therapy. However, it is also conceivable that bladder or ureter lesions were not detected in those cases.

The low number of calcifications detected in the study groups may reflect the well-known deficiency of the ultrasound technique: fine lesions are frequently missed (BURKI et al., 1986). For technical reasons it was not possible to investigate a number of doubtful cases of calcified lesions by X-ray. Nine cases could be identified by their typical echo-dense structure with conical shadow. Two of them cleared within 2 months, and the remaining 7 within 6 months, after treatment with $40 \mathrm{mg} / \mathrm{kg}$ of praziquantel. This clearance contrasts with findings of previous investigators (MACDONALD et al., 1968), who saw no clearance of bladder calcifications. One factor explaining these observations may be the lower efficacy of the drugs used at that time. Spontaneous resolution of uropathy is often assumed to occur. It is likely that some of the pathology seen in our study groups would have cleared without treatment. The benign nature of many lesions suggests that this could be the case.

We found that $20 \mathrm{mg} / \mathrm{kg}$ and $40 \mathrm{mg} / \mathrm{kg}$ of praziquantel showed comparable efficacy. The geometric mean egg output dropped in both groups to low numbers within one month, and the results were sustained up to 6 months (Table 1). The parasitological clearance rates (Table 2) showed that heavy infections had a substantially lower response to either treatment than light infections. Although our study indicates comparable efficacy, larger trials are needed to confirm these findings. The design of these trials should also include randomization within villages or areas, to overcome possible bias due to individuals in an area with more severe pathology tending to be given higher doses, as might have been the case with the present design.

The parasitological clearance rates in our study were higher than those recorded in previous studies (TAYLOR et al., 1988; WILKINS \& MOORE, 1987). This may have been due to the lower egg output of our subjects. It also suggests the possibility of geographical differences, which have to be considered 
for every schistosomiasis control project. Besides possible problems of development of resistance of the schistosomes to praziquantel, and the extreme care that must be taken when administering praziquantel in an area where cysticercosis is present (not the case in our district), operational and economic considerations must be taken into account before deciding on a treatment policy in an endemic setting.

The use of ultrasonography to detect lesions related to $S$. haematobium infection is well established (KING et al., 1988). Ultrasound is the least invasive method to assess morbidity and clinical importance in populations of endemic areas. Hence it can be used for decision making concerning public health measures and to monitor control programmes in progress (TANNER, 1989). In addition to laboratory and socio-economic parameters to monitor $S$. haematobium control projects, ultrasound should be used on a representative sample of the population covered by such projects. Following the conceptual change in schistosomiasis control from the control of transmission to the reduction of morbidity, the issues of treatment and retreatment strategies are key elements and require a number of comparative studies on the evolution of schistosome-related morbidity in various endemic settings.

\section{Acknowledgements}

We thank the pupils, their parents and teachers for their cooperation, and the technical staff of the Swiss Tropical Institute Field Station for their skilful assistance. We also thank Dr R. Meudt for his encouraging support. Research clearance was granted by the Tanzanian National Scientific Research Council (NSR/RA 47). The study was partially financed by the Swiss Directorate for Development Cooperation and Humanitarian Aid.

\section{References}

Aisen, A. M. (1983). Computed tomography of ureterovesical schistosomiasis. Foumal of Clinical Ultrasound, 8, 239-240.

Brinkmann, U., Werler, C., Traore, M. \& Korte, R. (1988). The national schistosomiasis control programme in Mali, objectives, organisation, results. Tropical Medicine and Parasitology 37, 215-219.

Burki, A., Tanner, M., Burnier, E., Schweizer, W., Meudt, R. \& Degrémont, A. (1986). Comparison of ultrasonography, intravenous pyelography and cystoscopy in detection of urinary tract lesions due to Schistosoma haematobium. Acta Tropica, 43, 139-151.

Degrémont, A., Burki, A., Burnier, E., Schweizer, W., Meudt, R. \& Tanner, M. (1985). Value of ultrasonography in investigating morbidity due to Schistosoma haematobium infection. Lancet, $i, 662-665$.
Doehring, E., Reider, F., Schmidt-Ehry, G. \& Ehrich, J. (1985). Reduction of pathological findings in urine and bladder lesions in infection with Schistosoma haematobium after treatment with praziquantel. Foumal of Infectious Diseases, 152, 807-810.

Ellenbogen, P., Scheible, F., Talner, L. \& Leopold, G. (1978). Sensitivity of gray scale ultrasound in detecting urinary tract obstruction. American foumal of Roentgenology, 130, 731-733.

Forsyth, D. (1965). Urological complications of endemic schistosomiasis in schoolchildren. Part 1. Usagara school. Transactions of the Royal Society of Tropical Medicine and Hygiene, 59, 171-178.

King, C. H., Lombardi, G., Lombardi, C., Greenblatt, R., Hodder, S., Kinyanjui, H., Ouma, J., Odiambo, O., Bryan, P. J., Muruka, J., Magak, P., Weinert, D., Mackay, W., Ransohoff, D., Houser, H., Koech, D., Arap Siongok, T. K. \& Mahmoud, A. A. F. (1988). Chemotherapy-based control of schistosomiasis haematobium. I. Metrifonate versus praziquantel in control of intensity and prevalence of infection. American foumal of Tropical Medicine and Hygiene, 39, 295-305.

Macdonald, G., Forsyth, D. \& Rashid, C. (1968). Urological complications of endemic schistosomiasis in schoolchildren. Part 4. As modified by treatment. Transactions of the Royal Society of Tropical Medicine and Hygiene, 62, 775-781.

Morin, M. \& Baker, D. (1979). The influence of hydration and bladder distension on the sonographic diagnosis of hydronephrosis. Foumal of Clinical Ultrasound, 7, 192194.

Suter, R. (1986). The plant molluscicide Swartzia madagascariensis and its application in transmission control measures against Schistosoma haematobium. Experience from Kikwawila (Kilombero District, Tanzania). Thesis, University of Basel.

Tanner, M. (1989). Evaluation and monitoring of schistosomiasis control. Tropical Medicine and Parasitology, in press.

Taylor, P., Murare, H. \& Manomano, K. (1988). Efficacy of low doses of praziquantel for Schistosoma mansoni and $S$. haematobium. Foumal of Tropical Medicine and Hygiene, 91, 13-17.

WHO (1985). The control of schistosomiasis. Geneva: World Health Organization, Technical report series No. 726.

Wilkins, H. \& Moore, P. (1987). Comparative trials of regimes for the treatment of urinary schistosomiasis in The Gambia. Foumal of Tropical Medicine and Hygiene, 90, 83-92.

Zumstein, A. (1983). A study of some factors influencing the epidemiology of urinary tract schistosomiasis at Ifakara (Kilombero District, Morogoro Region, Tanzania). Acta Tropica, 40, 187-204.

Received 12 May 1989; revised 27 fuly 1989; accepted for publication 27 fuly 1989 